\title{
Redes sociais e capital social na formação de redes socioprodutivas: Estudo em uma feira de confecções de Fortaleza
}

\author{
Regina Heloisa de Oliveira Maciel ${ }^{1}$, João Bosco Feitosa dos Santos², Tereza \\ Gláucia Rocha Matos ${ }^{3}$, Luciana Maria Maia ${ }^{4}$, Marselle Fernandes Fontenelle ${ }^{5}$
}

Este ensaio discute as noções de trabalho informal, redes sociais e capital social na busca pela proposição de uma reflexão para o que se denomina de redes socioprodutivas, tendo como campo empírico as feiras do Centro de Fortaleza. Para marcar os aspectos da informalidade e as características das redes que sustentam esse tipo de atividade, foi realizada uma entrevista em profundidade com um produtor/feirante. Também se incluíram observações in loco e pesquisa bibliográficodocumental, que auxiliaram na contextualização histórica das feiras e na descrição da informalidade em Fortaleza, tendo como fontes matérias de jornais e dados dos órgãos oficiais do Governo. Nas considerações finais, mostra-se que o estudo das feiras, com suporte nesse ponto de vista, pode melhor esclarecer as vivências dos trabalhadores, produtores/ feirantes, que vivem e sobrevivem da informalidade e discute-se o potencial desse enfoque para o entendimento das atividades que ocorrem nas feiras e das relações sociais e produtivas que ali se estabelecem, propondo a expressão "rede socioprodutiva" para instigar o debate que deve ser considerado em outros estudos.

Palavras-chave: Setor informal, Capital Social, Feiras, Setor de Confecção, Redes Socioprodutivas.

Social networks and social capital in the formation of socio-productive networks: Study in a downtown garment street market of Fortaleza

This essay discusses the concepts of informal work, social networks and social capital, intending to propose a reflection to what is called socio-productive networks, having the downtown street markets of Fortaleza as empirical field. To check the informality aspects and the characteristics of the networks that sustain this type of activity, an in-depth interview with a manufacturer/seller was held. Field observations and a bibliographic-documentary research were also included, which allowed a historic contextualization of this kind of market and a description of informality in Fortaleza, having newspaper materials and data from official Government institutions as sources. In the final considerations, we show that the study of the street markets, based on this point of view, can better clarify the experience of the workers, producers/salespeople, who live and survive from informality. We discuss the potential of this approach to the understanding of the activities that occur in the market and the social and productive relations that are established, proposing the expression "socio-productive network" to instigate a debate that should be considered in other studies.

Keywords: Informal sector, Social Capital, Street markets, Manufacturing sector, Socio-productive Network.

\section{Introdução}

\footnotetext{
A s mudanças ocorridas nas últimas décadas no mundo do trabalho apontam para a concentração de renda, redução do emprego formal e aumento da desigualdade social. Segundo Durães (2002), a escassez de empregos, a exigência de qualificação profissional e a flexibilização das relações de trabalho obrigam os trabalhadores a se submeterem a condições laborais precárias, mediante a percepção de baixa remuneração e falta de respaldo das leis trabalhistas. Tal situação propicia o surgimento de um conjunto de atividades que compõem a

1 Doutora em Psicologia. Professora Titular do Curso de Psicologia da Universidade de Fortaleza e do Programa de Pós-Graduação em Psicologia.

2 Economista, Doutor em Sociologia. Professor Adjunto da Universidade Estadual do Ceará, do Curso de Ciências Sociais e do Mestrado de Políticas Públicas e Sociedade.

3 Doutora em Psicologia. Professora Adjunta da Universidade de Fortaleza do Curso de Psicologia e do Programa de Pós-Graduação em Psicologia.

4 Doutora em Psicologia. Professora Adjunta da Universidade de Fortaleza do Curso de Psicologia e do Programa de Pós-Graduação em Psicologia.

5 Mestre em Psicologia. Professora Auxiliar da Universidade de Fortaleza do Curso de Psicologia.
} 
economia informal, fundamental para a inserção dos indivíduos no mercado de trabalho, além de garantir sua sobrevivência e reconhecimento social.

O setor informal é responsável pela maior parte das ocupações no mercado de trabalho nas últimas décadas. Em Fortaleza, o percentual de informalidade ultrapassa a metade percentual dos trabalhadores ocupados (Mesquita, 2008) e, dentre as atividades que mais crescem, destaca-se a venda de confecções, seja por ambulantes, seja por pequenos comerciantes permissionários de mercados e feiras livres na Cidade.

Esse tipo de comércio está em franco crescimento no município, de tal forma que a Prefeitura, preocupada com a "desorganização" dos feirantes, tem envidado esforços no sentido de fornecer locais adequados para a sua realização. No entanto, boa parte desses comerciantes ocupa hoje as ruas e as calçadas da cidade, principalmente no Centro. O número de vendedores de confecção vem se multiplicando, tornando perceptível a formação de redes que os mantêm unidos na ocupação de seus espaços de trabalho, bem como na fabricação e venda dos produtos que comercializam.

Neste trabalho, toma-se esse movimento de unificação dos vendedores/produtores das feiras de confecção como um exemplo para refletir sobre o que se denomina rede socioprodutiva, a serviço do fortalecimento de um comércio historicamente conhecido. Percebem-se, nesse contexto, as ramificações de vínculos e a formação de redes de solidariedade e confiança, ao mesmo tempo que os comerciantes e produtores buscam expandir seus negócios na conquista de clientes, por meio do envolvimento de familiares e amigos. Evidencia-se, assim, o "capital social" do qual se alimentam esses trabalhadores.

Buscou-se fazer uma reflexão sobre o trabalho informal e as redes sociais que compõem e mantêm as feiras de roupas do Centro de Fortaleza, Ceará, com o objetivo de debater as noções de informalidade, redes sociais e capital social e suas relações, tendo como pano de fundo uma das feiras do Centro da Cidade.

\section{Trabalho informal}

A noção de informalidade é bastante controversa e envolve interpretações diversas, dependendo do objeto de estudo. O termo "setor informal" tem origem nos trabalhos produzidos pela Organização Internacional do Trabalho (OIT), em 1972, sobre as condições dos trabalhadores do Quênia, na África, que desenvolviam suas atividades em condições precárias e desprovidos de qualquer proteção legal. Esse documento é considerado um marco na delimitação do conceito de informalidade e seu propósito era definir "uma categoria de análise que descrevesse as atividades geradoras de rendas relativamente baixas e aglutinasse os grupos de trabalhadores mais pobres no meio urbano" (Dalbosco \& Kuyumjian, 1999, p. 204).

Cacciamali (2000) destaca que o fenômeno da informalidade é abrangente e remete a inúmeras atividades econômicas de natureza heterogênea, propondo o emprego da expressão "economia informal" em vez de "setor informal", pois a informalidade atinge diferentes setores. Os trabalhos terceirizado, autônomo, temporário e ilegal, e o comércio de rua ou ambulante, que envolve a sonegação fiscal, são exemplos das atividades que fazem parte da chamada economia informal. O elemento comum na definição das atividades informais é que são situações em que as regras não estão bem estabelecidas

[...] em lei ou em procedimentos usuais. Assim, as recorrentes menções a este tema no momento presente refletem as dificuldades que as organizações, os indivíduos e o coletivo social vêm enfrentando para superar, com as regras legais vigentes ou os procedimentos-padrão, as mudanças estruturais econômicas, políticas e sociais em andamento (Cacciamali, 2000, p. 153). 
Os elementos que caracterizam o informal no relatório da Organização Internacional do Trabalho (OIT, 1972), são: (a) propriedade familiar do empreendimento; (b) origem e aporte próprio dos recursos; (c) pequena escala de produção; (d) facilidade de ingresso; (e) uso intensivo do fator trabalho e de tecnologia adaptada; (f) aquisição das qualificações profissionais à parte do sistema escolar de ensino; e (g) participação em mercados competitivos e não regulamentados pelo Estado (Cacciamali, 2000).

É importante destacar, nesse passo, a existência de dois domínios distintos: o da economia informal e o do trabalho informal (Charmes, 2009). O trabalho informal pode existir tanto na economia formal quanto na informal. $\mathrm{Na}$ economia informal, compreende o autoemprego (autônomos, empregadores, trabalhadores familiares) e o emprego em microempresas (empregadores e empregados de microempresas em quantidade de até cinco funcionários). Já na economia formal consiste naquele realizado por empregados de microempresas ou domésticos sem proteção social. Há ainda um terceiro conceito - o de "economia subterrânea" - que remete diretamente à existência de empresas ou negócios não legalizados, mas não necessariamente ilegais ou ilícitos.

Jütting e De Laiglesia (2009) acreditam que o trabalho informal é a norma e não a exceção. Sua tendência é de aumento, mesmo nos países desenvolvidos. Para os autores, a questão da informalidade é problemática tanto para os indivíduos quanto para a sociedade. Do ponto de vista do indivíduo, o trabalho informal o situa fora da proteção do Estado, portanto, em situação de vulnerabilidade social. No entanto, apesar de, na maior parte das vezes, estar relacionado à pobreza e à precariedade, pode significar também maior mobilidade social e melhores oportunidades, visto que, em algumas regiões, o acesso ao trabalho formal de qualidade é praticamente inexistente (Gagnon, 2009). Assim, o trabalhador informal pode tanto ter sido excluído do mercado formal quanto ter optado por essa solução em busca de melhores condições de vida. Do mesmo modo, os negociantes podem ter optado pela economia informal em razão de ineficiências e regulamentações demasiadas do Estado (Jütting \& De Laiglesia, 2009).

Entre 2000 e 2008, pesquisa do Instituto de Desenvolvimento do Trabalho (IDT, 2008), em Fortaleza, revelou que o aumento de empregos com carteira assinada, verificado no período, foi acompanhado por um ritmo mais intenso de crescimento no mercado informal. Já na década de 1990, Meneleu (1994) acentuava que o trabalho informal aumentava com a crise, mas também crescia com a recuperação econômica. Mesquita (2008) chegou a semelhante conclusão, enfatizando que mesmo em um período de expansão do emprego formal, a informalidade aumenta, sinalizando que a questão envolve outras variáveis, além do comportamento do mercado formal, tais como crescimento demográfico e densidade populacional, desempenho econômico e setorial, luta pela subsistência e exploração do trabalho, dentre outras. $\mathrm{O}$ autor conclui que a elevação do nível de informalidade é motivada pelo maior crescimento da economia nacional, nos últimos anos, o que fomenta maior consumo de massa e possibilita a abertura de novas oportunidades de trabalho. As ocupações informais, porém, cresceram em um ritmo mais acelerado, especialmente no que concerne aos trabalhadores autônomos, ou por conta própria, que já representam quase $1 / 3$ da população ocupada na Capital cearense. Dados da mesma pesquisa mostram que os trabalhadores informais na região metropolitana de Fortaleza representavam, ao final do ano de 2009, nada menos do que 54,6\% do total de ocupados, o que significava 460.104 pessoas. Ressalta-se o significativo crescimento de postos de trabalho com carteira assinada e da economia cearense nos dois governos do presidente Lula, via de regra, a taxas maiores do que a média nacional, justificando a importante observação dos autores sobre o caráter de interdependência do crescimento das ocupações informais e o crescimento econômico.

A relevância de uma melhor compreensão do trabalho informal e de como vivem seus exercentes se justifica tanto pelo seu aumento real nos últimos anos quanto pela constatação de 
que grande parte dele ocorre em condições de trabalho bastante precárias (Quinlan, 2009). Por outro lado, favorece o desenvolvimento do chamado capital social, no sentido proposto por vários autores, como Bourdieu (1980), Coleman (1988) e Putnam (1996), ao mesmo tempo em que configura redes sociais, capazes de fornecer certo suporte aos trabalhadores, embora nem sempre isso seja abordado nos estudos e pesquisas sobre a informalidade.

\section{Redes Sociais e Capital Social}

Redes sociais são sistemas complexos compostos por agentes que estabelecem diversos tipos de relações. Na atualidade, as redes sociais estão em evidência, principalmente em vista do avanço tecnológico que permitiu a expansão dos grupos e das relações entre atores em variados territórios geográficos. Assim conceituadas, as redes sociais e as metodologias para sua análise povoam a literatura sobre o desenvolvimento social (Hatala, 2006).

As redes sociais, segundo France (2006), possuem duas vertentes: uma estrutural, que se atém ao estudo das estruturas, sem considerar o tipo e a forma das relações; e uma relacional, referente às condições sociais e políticas na sua formação e manutenção. Além da estrutura, a rede social é permeada de valores, de subjetividade e de construção compartilhada. A autora aponta as dificuldades de se estabelecer os limites de uma rede social, principalmente levando-se em conta o desenvolvimento tecnológico atual, que permite o estabelecimento de relações em uma escala mundial e a influência de inúmeros fatores sobre uma rede local. Fredericks e Durland (2005) enfatizam que a teoria atual sobre redes sociais e sua análise focalizam o contexto social e o comportamento das relações entre os agentes, e não as escolhas individuais, foco principal nos estudos tradicionais da Sociologia e da Psicologia, uma vez que sua ênfase é sobre as relações entre as pessoas que compõem a rede, permitindo, assim, melhor compreensão dos fenômenos psicossociais.

Abramovay (2002), referindo-se à questão das desigualdades regionais no desenvolvimento rural, afirma que, no estudo das razões que levam determinadas regiões a se desenvolverem mais do que outras, o importante é investigar "[...] o fenômeno da proximidade social que permite uma forma de coordenação entre os atores capaz de valorizar o conjunto do ambiente em que atuam e, portanto, de convertê-lo em base para empreendimentos inovadores" (p. 113). Segundo o autor, para se entender as desigualdades regionais, deve-se estudar a montagem das redes, convenções e instituições que permitem ações cooperativas que aumentem a inclusão no acesso a bens públicos, como a educação, a saúde e a informação, e que enriquecem o tecido social de certa região.

Portanto, para o conceito de redes sociais, convergem diversas tradições teóricas que focalizam o desenvolvimento social e os conteúdos das relações entre indivíduos na manutenção de suas necessidades. Essas relações podem ser entendidas dentro da proposta de Certeau (1994), que desenvolveu os conceitos de "estratégia" e de "tática" para compreender as práticas que constroem o cotidiano. As estratégias se referem às relações de força inseridas nas redes sociais e as táticas são as práticas em que se engajam os indivíduos que compõem a rede para produzir resultados imediatos, o "fruto da convivência cotidiana". As estratégias se relacionam com o poder exercido em um lugar ou instituição e as táticas se vinculam à "astúcia popular". Para se compreender como são formadas as estratégias e táticas no interior de uma rede, é necessário entrar na esfera cotidiana, conhecendo seus aspectos simbólicos, sua história, seu senso comum e as identidades que a permeiam (Carrieri, Souza \& Almeida, 2008).

A questão das estratégias e táticas do cotidiano foi abordada por Sato (2006) em seus estudos sobre as feiras livres da cidade de São Paulo. Um dos feirantes entrevistados define a feira livre como uma "bagunça organizada", expressão que compatibiliza duas formas organizativas 
aparentemente antagônicas: a anarquia, capacidade organizativa autônoma, que convive com uma suposta padronização centralmente definida, mostrando a relação entre a estrutura, ou estratégia organizativa, e as táticas de uso das estratégias impostas pelas autoridades.

O conceito de capital social parece também convergir para o de redes sociais. Segundo a definição inicial feita por Bourdieu (1980), e expandida por Coleman (1988), capital social é o conjunto de recursos atuais ou potenciais ligados à pertença a uma rede de relações duráveis, mais ou menos institucionalizadas, de conhecimentos e reconhecimentos mútuos entre as pessoas. Assim, a rede social proporciona trocas baseadas no capital social do grupo ou rede, formalmente constituída ou não. Putnam (1996) redefine esse conceito para abranger as relações potenciais, estendendo-o a sociedades inteiras e regiões geográficas, embora as conclusões obtidas nem sempre sejam apoiadas por evidências empíricas (Portes, 2000). No sentido dado por Bourdieu, o conceito de capital social soma-se ao de rede, favorecendo o entendimento das trocas que ocorrem em seu interior.

A rede social, "[...] espinha dorsal da vida social e econômica" (Eagle, Macy \& Claxton, 2010, p. 1029), constitui, portanto, as teias de significados nas quais os recursos do capital social e seu fator característico - a confiança - podem se expandir. O capital social, por sua vez, torna-se cada vez mais forte quanto maior é o seu uso. Assim, pode-se inferir que a confiança é uma espécie de combustível, que alimenta tanto o capital social quanto as redes de trabalho informal, que se quer definir aqui, denominando-as de "redes socioprodutivas".

Um estudo interessante sobre redes sociais foi o realizado com crianças de rua no Kenya (Ayuku, Odero, Kaplan, Bruyn \& De Vries, 2003), com base na Análise de Redes Sociais de Maastricht. De acordo com os autores, uma rede social pode ser definida como todas as pessoas e grupos, expressos em termos de pessoas reais, com os quais alguém mantém laços mais ou menos duradouros que satisfazem as necessidades cotidianas da vida de uma dada pessoa-chave. A estrutura desse coletivo consiste de outras pessoas (membros da rede) e de laços que fornecem a forma e a substância do acesso da pessoa-chave (pessoa foco) às suas necessidades psicossociais básicas. Essa estrutura pode ser dividida em vários "grupos setoriais", classificados de acordo com sua natureza ou origem. $\mathrm{O}$ modelo de Maastricht divide a rede em grupos familiares, de amigos e fornecedores de serviços. Esses setores podem ser ainda subdivididos em unidades menores, denominadas de "clusters", que variam de acordo com o objetivo e a população estudada. Outros elementos incluem: "variedade", medida por diferenças nas características sociodemográficas; e "acessibilidade", mensurada pela distância geográfica da pessoa-foco. As características dos laços entre a pessoa-foco e os membros da rede fornecem informações adicionais e incluem frequência e iniciativa de contato, amplitude e peso. O peso é especialmente importante porque mede o grau com que o laço satisfaz as necessidades psicossociais básicas da pessoa-foco, isto é, fornece apoio social. Quatro necessidades podem ser diferenciadas: afetivas (de ser amado, apreciado, considerado confiável e ter apoio emocional); de contato (pertença, segurança, obtenção de apoio do outro baseado no interesse comum, valores e origem); de estabilidade (ter laços habituais, duradouros e igualmente distribuídos); e materiais e instrumentais (moradia, alimento, informação e assistência). Resumindo, a teoria pressupõe a existência de "nós", ou de agentes que compõem a rede. Uma rede é feita de "nós" relacionados dentro de uma "estrutura". No caso das redes sociais, os "nós" são, evidentemente, os participantes dessa estrutura que mantêm trocas, comunicações e relações com os outros participantes (Butts, 2009).

As redes podem ser entendidas como os elementos básicos que compõem o capital social de um determinado grupo e como o terreno de onde emergem as táticas cotidianas. O fazer e o saber dos "nós", bem como as relações entre eles, é que fornecem a dinâmica social a interagir com as estratégias organizativas de forma positiva ou negativa. Assim, as atividades e relações ocorrentes no trabalho informal das feiras podem ser mais bem compreendidas sob a óptica das redes sociais 
e do capital social proporcionado por elas. Para diferenciar o conceito utilizado aqui do sentido mais comum dado a redes sociais, propõe-se denominar o fenômeno de "redes socioprodutivas".

\section{As feiras e suas dinâmicas}

Atualmente, as feiras possuem caráter popular e mantêm a forma tradicional de comércio - baseada na relação face a face - de maneira a resistir ao surgimento das modernas formas de consumo e à difusão de outros modos de atuação decorrentes da globalização. As feiras são capazes de absorver as mudanças e de se readaptar a partir da criatividade popular (Dantas, 2008).

As feiras populares de confecções são comuns no nordeste brasileiro. Lira (2008) referese ao comércio da região do agreste de Pernambuco, onde predominam pequenas empresas de confecção, como "sulanca". Essa denominação é uma corruptela das palavras "sul" e "helanca", designando produtos de vestiário confeccionados com malhas vindas do sul do país e vendidos nas feiras ou mercados populares das cidades nordestinas e em alguns pontos comerciais das grandes cidades, como São Paulo (Lyra, 2005), a preços baixos, que alimentam um comércio de grandes proporções. A "sulanca" do agreste pernambucano ficou conhecida como a feira que possui produtos simples, de qualidade inferior e preços acessíveis a camadas da população de baixa renda, embora convivam nesses espaços produtos de melhor qualidade.

Em Fortaleza, até bem pouco tempo, esse tipo de feira de confecções estava, prioritariamente, concentrado no chamado Beco da Poeira. Criado em 1989, era um mercado permanente de confecções e de outros produtos industrializados, de baixo custo, inicialmente localizado entre duas praças do Centro da Cidade. Em 2010, os trabalhadores foram transferidos para um local próximo, instalando-se em uma antiga fábrica situada a duas quadras do local. Esse novo local é chamado de "Novo Beco", embora tenha recebido o nome oficial de Centro de Pequenos Negócios (CPN).

A retirada do Beco da Poeira de seu local original e a escolha de um novo ponto para esses comerciantes não foi um processo tranquilo, porquanto atravessado por várias disputas entre a Prefeitura e os comerciantes, principalmente em razão de as autoridades não terem cumprido a promessa de instalar a feira em um prédio amplo entre a Avenida Tristão Gonçalves e a Rua 24 de maio, ao lado do antigo espaço, interrompendo as obras antes de sua conclusão. Cerca de 500 permissionários e feirantes do antigo centro comercial, entre um universo de pelo menos 1700 comerciantes e outros trabalhadores, geralmente informais, em protesto, ocuparam o prédio apelidado de "Esqueleto", em menção ao fato de apresentar apenas a estrutura do que deveria ser o novo Beco da Poeira, e cujos boxes já haviam sido adquiridos por eles, e começaram a comercializar seus produtos (Lazari, 2010).

Outro centro de vendas de roupas de baixo custo, mais recente, pode ser encontrado nas ruas próximas à Catedral. Silva, Santos e Silva (2010) explicam que, inicialmente, uma parte da rua era ocupada por um grupo pequeno de bordadeiras, que expunham seus produtos em lonas colocadas no chão. Na continuidade, a feira começou a atrair produtores e intermediários de produtos artesanais e industriais, regionais e nacionais, alcançando grandes proporções e transformando-se em uma referência nacional no comércio de confecção, merecendo bastante atenção da mídia.

Salvi (2008), em reportagem para O Povo, mostra a extensão desse comércio e sua rede, agora facilitado com a possibilidade de utilização de cartão de crédito, e fala da polêmica que cerca o tema, envolvendo denúncias sobre a ocupação de espaço público para interesses particulares, a irregularidade da situação dos comerciantes e a suspeita de que entre eles existam representantes dos lojistas, que, não obstante sirvam de pauta para constantes confrontos entre feirantes e autoridades, não impedem que a cada semana o número de compradores que chega do interior do estado do Ceará e de outros estados do Nordeste continue expressivo. 
Por causa das dificuldades de circulação no Centro, provocadas por esse comércio, o Poder Público resolveu retirá-lo do local onde funcionava, transferindo os comerciantes para o "Feira Center”, em Maracanaú (município da Região Metropolitana de Fortaleza). Contudo, parte dos ambulantes continuou no Centro, instalando-se nas proximidades da Catedral, na Rua José Avelino, ocupando antigos galpões que lá existiam. Os que haviam ido para o município de Maracanaú em pouco tempo voltaram, e os comerciantes do Centro de Pequenos Negócios também colocaram barracas no local.

Atualmente, a "Feira da José Avelino" (Figura 1) ocorre com os feirantes trabalhando tanto nos galpões como fora deles, na rua. Os galpões somam um total de 11 e cada um tem espaço para inúmeros boxes. Dos feirantes é cobrada uma taxa correspondente ao aluguel do box, cuja infraestrutura é bastante precária.

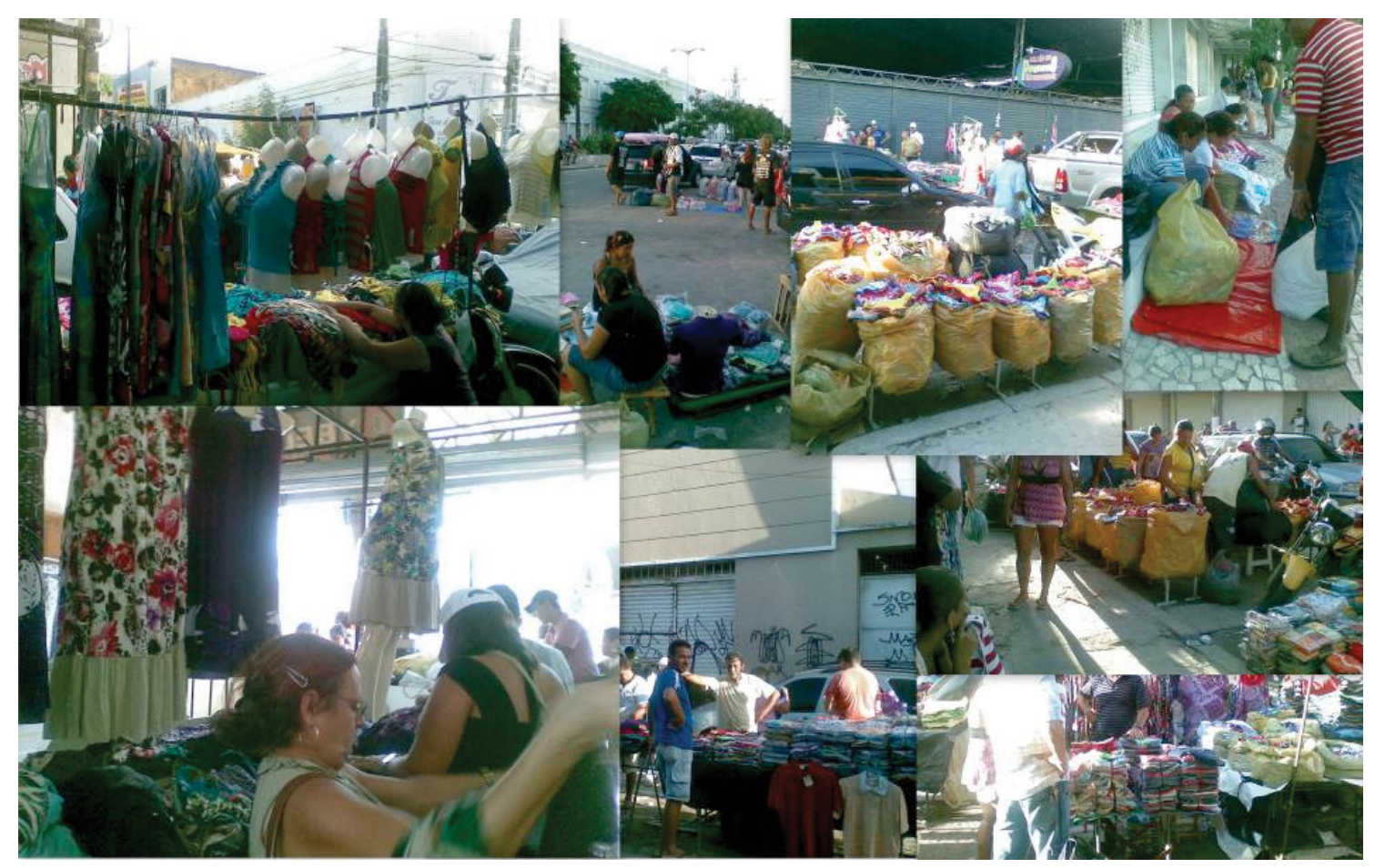

Figura 1. Imagens da feira da José Avelino.

Toniatti (2008), por sua vez, escreve sobre o embate dos feirantes com as autoridades locais para manter a feira funcionando, bem como a força da rede social que mantém o comércio e a produção das roupas, que deu seus primeiros passos a partir da iniciativa de bordadeiras de Itapajé, que comercializavam toalhas e colchas para lojas nas cercanias da Praça, de trabalhar por conta própria, diretamente para o consumidor final. Uma feirante relata que, no início, "Éramos umas 20. Cada uma tinha seu canto. Aí a notícia se espalhou”. Toniatti (2008) discute o que considera a história de tantas feiras existentes em locais públicos de Fortaleza, observando que as primeiras feirantes estavam dando início a uma feira que chega, atualmente, a reunir três mil comerciantes em dias de pico. Ainda de acordo com o relato de um outro feirante que "estende a lona [na Praça] há seis anos", é tudo "uma viração", tendo em vista que também é locatário de um box nos fundos do Novo Beco da Poeira (CPN).

Um dos maiores problemas constatados é a interferência da feira na passagem dos transeuntes, "principalmente nos sábados, quando a feira fica armada até 18 horas e toma todo o calçadão. $O$ inchaço é consequência do 'sucesso' da feira”, explica Toniatti (2008), que de tão grande tem suscitado o aparecimento de novas ocupações, como a de "guardador de lugar". Alguns feirantes precisam pagar para garantir que, quando chegarem, todos os dias, o lugar onde expõem estará 
reservado. A proprietária de uma loja na Rua João Moreira, quando interpelada sobre o avanço da feira contra o espaço de trânsito do cidadão, respondeu o seguinte, como citado por Toniatti (2008):

Não tenho nada contra, muita gente sobrevive daí dignamente, mas encosta um, outro e depois não tem limite, vai se complicando. Eles tiram o direito do cidadão que quer passar na rua... Na segunda e quinta-feira, dias mais movimentados, as lonas se estendem pela calçada da 10 ${ }^{\underline{a}}$ Região Militar, ocupam o ponto de ônibus, entram na Rua José Avelino, lotam o viaduto e sobem a Rua Dr. João Moreira. Os ônibus têm dificuldade de passar, os carros só têm uma faixa, as vagas são ocupadas por feirantes, o trânsito para enquanto a feira é desmontada. Um caos (s/p).

Outra questão apontada por Toniatti (2008) é a privatização do espaço público, perceptível pelas "faixas pintadas no asfalto, demarcando áreas reservadas para as lonas" e provocadora de tensão e embates entre feirantes e autoridades. $\mathrm{O}$ fato de a justiça ter determinado a retirada dos feirantes do local tem sido motivo de revolta e descrença, por parte de alguns. Segundo um dos feirantes citados na reportagem "É mais política. Tem tempo que ameaçam... Se acabar aqui, vai ter que acabar na José de Alencar também”, provoca. Toniatti (2008) conclui afirmando que "Com o comércio consolidado, qualquer tentativa de normatização tende a virar conflito".

O maior movimento da feira ocorre nas madrugadas de quinta e segunda-feira, quando são recebidos compradores, não só de Fortaleza, mas de todo o Ceará, de outros estados do Nordeste e de Cabo Verde. Ainda segundo Toniatti (2008), 33,6\% dos feirantes ganham entre 300 e 600 reais por mês; $76,4 \%$ são pequenos fabricantes que mantêm ateliês em casa ou terceirizam a costura; e apenas $23,6 \%$ são revendedores. A feira é uma espécie de polo da confecção e revigorou a região, levando lojas para o seu entorno.

Lira (2008) acentua que as relações capitalistas que conformam esse tipo de produção e comércio são marcadas por uma precarização muito forte das relações de trabalho, porque a maioria dos empreendimentos se encontra na informalidade. Nesse contexto, amplia-se a exploração dos trabalhadores, baseada na ausência de regras formais, e evidencia-se um regresso nas condições de vida da maioria da população.

Nota-se, pelos relatos sobre os conflitos e as disputas que ocorrem no âmbito desse tipo de comércio, a importância da feira para esse grupo populacional que vive do trabalho informal. Notase, também, a organização do grupo, que permite deduzir a existência de uma rica rede de relações (redes socioprodutivas), que impõe suas táticas de sobrevivência às estratégias do Poder Público.

No que se refere às estratégias da Prefeitura, percebe-se seu interesse em transformar a estética do Centro da Cidade, organizando os vendedores ambulantes de modo a devolver aos transeuntes as praças e as ruas do Centro, concentrando-os, por conseguinte, em espaços específicos, conforme as modalidades definidas (ambulantes, feirantes, camelôs etc.).

\section{A Narrativa de um Participante de Rede Socioprodutiva}

Com o intuito de ilustrar as razões e estratégias dos feirantes que trabalham e sobrevivem da feira da José Avelino, foi realizada uma entrevista com um feirante/produtor que mantém comércios tanto no CPN ("Novo Beco"), quanto nos arredores da Rua José Avelino, fato comum desde o desmonte do Beco da Poeira. A entrevista foi realizada a partir de um convite ao jovem trabalhador e ocorreu nas dependências da universidade. Ao participante foram explicitados os objetivos da entrevista e foi-lhe solicitado que assinasse um Termo de Consentimento Livre e Esclarecido. 
A análise da entrevista permitiu identificar algumas características das redes que se estabelecem nas feiras de roupas do Centro de Fortaleza, assim como evidências da informalidade e precariedade das condições e organização de trabalho ali estabelecidas. A narrativa desse feirante configura significados que, per se, demonstram características de sociabilidade e laços produtivos, mesmo em meio a condições de precariedade.

\section{Alternativa ao emprego formal}

O primeiro elemento que se pode destacar diz respeito à feira como espaço de sobrevivência, locus para fugir do desemprego e/ou dos baixos salários, uma das razões para o aumento dos empregos informais (Jütting \& De Laiglesia, 2009). O entrevistado relata:

Muitos não tem carteira assinada é tudo informal... às vezes não ganha um salário. Além de não ganhar o salário, às vezes não ganha alimentação... Porque são pessoas que precisam trabalhar e se dispõem a ganhar $\mathrm{R} \$ 300$ reais pra trabalhar de segunda a sábado (Ent.).

Outra representação que se nota no discurso e que parece contribuir para que as pessoas se submetam a precárias condições de trabalho e a sua organização caótica está associada à expectativa de mudança de vida e ao desejo de ter o próprio negócio. De fato, permanecer naquelas condições não é a vontade da maioria, entretanto, o sonho do "próprio negócio" prevalece em relação ao emprego formal, o que denota uma vocação desse contingente populacional para a atitude informal autônoma. Essa constatação corrobora as afirmações de Charmes (2009) sobre as razões da opção pelo trabalho informal.

Se você chegar lá e perguntar qual o seu maior sonho, a grande maioria vai responder que é ter seu próprio negócio. Então, isso é uma tentativa de realizar sonhos... às vezes, o que motiva muita gente, até mesmo ser explorada, se colocar na posição de ser explorado, é a esperança de que um dia vá sair daquela situação. Aí sofre de tudo (Ent.).

Tramas de sociabilidades e desproteção social

A relação entre os vários agentes que estruturam a feira pode, por um lado, favorecer o seu próprio funcionamento e, por outro, criar uma dependência entre feirantes e clientes, tendo em vista a informalidade dos negócios e vínculos, que pode levar ao fracasso. No caso da feira, a vulnerabilidade dessas relações aparece, por exemplo, na condição de dependência da rede e da falta de proteção social:

(...) um desses clientes conseguiu fazer com que a gente "quebrasse que apartasse", porque a gente fez mais ou menos a maior produção que a gente tinha feito na época, que era mais ou menos 10 mil... era muita coisa. E ele deu um cheque sem fundo, voltou. A gente teve que vender a casa (Ent.).

Nessa lógica de interdependência, em momentos de crise, todos da feira, de alguma forma, são afetados, assevera o informante:

E se tem uma crise dentro da feira não afeta só um, afeta tudo. Afeta todas as pessoas que estão trabalhando lá dentro, não é só a área da confecção infantil, não é só a área da peça íntima, não é só a área da camisaria, é todo mundo (Ent.). 
Nas relações estabelecidas na feira, entretanto, se pode perceber aspectos que parecem destacar o apoio social e a rede de solidariedade subjacente aos negócios e atividades desenvolvidas, mostrando que a opção por esse tipo de emprego não é apenas uma escolha baseada na falta de um emprego melhor, mas motivada pela possibilidade que oferece de fugir da falta de qualidade dos empregos formais (Charmes, 2009):

Isso é o legal do Beco da Poeira, você ri o dia todo, você não para de rir pelo menos para o estresse não ser maior... Tem que encontrar uma forma de escapar para algum canto, né. Porque se você já vai todo dia com uma insegurança que você provavelmente volte sem nenhum centavo para casa e você ficar com uma percepção voltada só para aquilo ali, você pira... eu cansei de trabalhar 3 anos seguidos no dia $1^{\circ}$ de maio. E eu ia com a maior alegria do mundo, porque eu sabia que quando chegasse lá, a gente ia ouvir música, ia brincar (Ent.).

\section{Tessituras da produção e precariedade}

A rede social estabelece diferentes relações e variados lugares para as pessoas que dela participam. As mercadorias à venda podem ser dos mesmos fabricantes e convivem, lado a lado, vendedores em concorrência aberta, mas em harmonia. Na fala do informante:

A gente fica no box alugado e a minha vizinha também, só que a mercadoria é nossa, a gente produz nossa mercadoria e vende. Tem até outras pessoas lá dentro que as pessoas compram a mercadoria pra vender, pra pagar aluguel, pra pegar mercadoria, alimentação, passagem, tudo. (Ent.)

A convivência com diferentes atores da feira e as estratégias e táticas dos feirantes ficam patentes na fala do entrevistado, quando descreve a figura do atravessador, que na feira de roupas de Fortaleza ganha o nome de "quengueiro".

Eles recebem o nome popular de "quengueiros", porque eles ganham dinheiro em cima da mercadoria das pessoas. Só que, geralmente, existe sempre um acordo de boca que eles chegam para o dono do Box e dizem: "eu trago pessoal pra ti, tuas vendas vão aumentar, só que eu ganho minha porcentagem em cima, eu boto meu valor em cima”. Eu já vi um quengueiro pegar uma senhora para vender uma bermuda que era 25 e ele vendeu por 50 reais. Coisa que um dono de Box, que é um pequeno empreendedor, vai demorar dois dias para ganhar daquele tanto (Ent.).

\section{Redes socioprodutivas}

Outra característica que se verifica na feira é a informalidade das relações de trabalho e as táticas adotadas na busca de seu espaço. “...a minha mãe chamava as costureiras para dentro né [para trabalhar dentro da própria casa do entrevistado], era um processo bem assim familiar”.

Ainda em relação à natureza dinâmica da rede, para se manterem ativos, os feirantes instituem opções de adaptação a novas contingências: as táticas produzidas no interior da rede.

Quando passou um pouco mais o tempo, aí minha mãe e meu pai viram que não era tão lucrativo ficar com as costureiras dentro de casa, aí o que foi que aconteceu a gente começou a doar as máquinas para que elas fizessem em casa. Aí a gente ficava lá em casa como uma espécie de facção, cortava, infestava, aplicava, porque também trabalhava com bordado e colagem. Aí aplicava e bordava e 
repassava para as costureiras, aí elas faziam a costura, e sempre pagando por produção, porque o maior problema sempre foi costureira, porque era uma dificuldade muito grande, porque elas trabalhavam o ano todinho até setembro, quando chegava setembro, outubro, deixavam a gente e iam trabalhar para quem pagasse mais caro (Ent.).

A lógica do trabalho na feira naturaliza a precariedade do trabalho, que parece ser reforçada pela perspectiva real de desemprego. Vários trechos da entrevista evidenciam a falta de proteção social, característica dos empregos não regulamentados, típicos do contexto das relações informais.

(...) lá é um campo muito fértil de se observar muito disso, dos processos tanto da questão de exploração - você consegue ver isso muito claro, pessoa que fica lá das $8 \mathrm{~h}$ da manhã até meia noite... porque o patrão obrigava, se fosse reclamar, ele dizia 'Quer não? Pois sai, porque tem outro que quer'. E realmente, tem outro que quer (Ent.).

Os ganhos dependem diretamente da comissão referente às peças vendidas: “...quando ele chega lá e dá 11 horas e ele não vendeu uma peça, é impossível não bater o desespero. Se o patrão chegar e abre o caixa com 3 mil reais, 'só 3 mil reais?' aí começa a pressão".

E as condições de trabalho são bastante precárias: "Eu já vi funcionário levando choque no meio das ferragens lá, caindo lá de cima pro chão, porque ficava lá separando as coisas e, às vezes, tocava num fio descascado sem querer".

A precariedade não se limita às relações de trabalho, mas parece fazer parte da própria organização da feira, das estratégias do Poder Público, envolvendo variados agentes. $\mathrm{O}$ trecho a seguir ilustra essas práticas de informalidade e ilegalidade.

A prefeitura começou a fazer o cadastramento de novas pessoas pra boxes ociosos, que ninguém sabia onde era que existiam esses boxes ociosos, porque a prefeitura já estava era devendo 60 boxes de gente que já estava morto e foi vendido os Boxes, as permissões, e estava uma confusão medonha. Inclusive, nisso, meu pai está em um processo na Justiça, não ganhou um box, porque ele comprou um box, uma permissão de um box do ex-presidente da APROVACE [Associação Profissional de Comércio de Vendedores Ambulantes do Estado do Ceará], que era quem cuidava dessa comitiva dos feirantes lá do Beco da Poeira, que ele foi retirado pela prefeitura. Ele perdeu o posto e a prefeitura assumiu e ele vendeu um box, de um tio que era morto, pro meu pai.

O presidente da APROVACE quando viu que o 'esqueleto' era uma possibilidade de encabeçar de novo uma cooperativa o que foi que ele fez? Juntou a massa e vendeu o produto que foi o que? Venha pra cá, você me paga que eu reservo o seu espaço com a sua banca (Ent.).

A forma como a feira se organiza não pode ser vista somente do ponto de vista negativo. A representação da feira como espaço de mercadorias mais baratas é reforçada, segundo os feirantes, pelo caos percebido pelos clientes:

A gente tem uma clientela muito de fora, são pessoas que vêm, que compram, e elas precisam de um lugar que venda muito e com preço muito barato e quando elas chegam no lugar limpo, bonito, elas acabam fazendo uma confusão de que a mudança faz com que o preço fique mais caro (Ent.).

Desse modo, os feirantes parecem atribuir à organização caótica e ao ambiente de trabalho inadequado fatores de competitividade. É possível que essa atribuição decorra da representação da feira como prática de sobrevivência básica e não de geração de lucros, como mostram os estudos de Sato $(2006,2007)$. 
O acesso à rede socioprodutiva

A natureza dinâmica das redes sociais facilita a entrada e a saída de agentes. No caso da feira de roupas, um critério que parece fundamental para sua ampliação é a confiança. A confiança e a informalidade das relações convivem, ao mesmo tempo, com a razão que determina o preço no mercado capitalista, o que denota a importância da existência da rede como pano de fundo do capital social (Abramovay, 2002). Segundo relata o informante:

Os clientes do Beco da Poeira funcionam assim: você está lá vendendo chega o cliente, faz uma pesquisa lá dentro do Beco da Poeira, quanto mais barato você fizer, ele se torna o seu cliente. Com o tempo, pela confiança ou por referência de outros feirantes que tem lá, você decide se vende no cheque ou não (Ent.).

Outra característica marcante nessa cadeia de produção e vendas diz respeito aos vínculos familiares que unem os diversos agentes, mesmo que comercializando produtos diferenciados.

A minha tia, que é irmã da minha mãe, ela começou trabalhando com a minha mãe, aí expandiu pra fazer as coisas dela, produzir também né e hoje em dia ela está na José Avelino. Aí hoje em dia o meu pai está tentando ver se consegue uma banca na José Avelino.

Tem gente que vai com a família inteira, tem gente que vem de Itapipoca e traz tapioca para vender, bolo de milho, e lá vai tentando fazer clientela (Ent.).

\section{Considerações finais}

Como se pode perceber pelo relato do produtor/feirante entrevistado, bem como pelo breve histórico sobre a formação da feira de roupas da Rua José Avelino no centro de Fortaleza, e, ainda, a partir dos embates dos produtores/comerciantes com o Poder instituído, a feira é muito mais do que um mero comércio. Ela representa a sobrevivência e o modo de vida de milhares de pessoas que, de um modo ou de outro, vivem desse processo socioeconômico.

O setor é eminentemente informal, com ocupações também informais. Com efeito, o chamado "polo de confecções" da feira da Rua José Avelino não pode ser considerado como um "arranjo produtivo local" (APL), dada a quase total informalidade dos negócios e atividades que lá se desenvolvem. Suzigan, Furtado, Garcia e Renato (2003) descrevem um tipo de APL denominado caótico e informal, mas a feira investigada aqui é mais do que isso, é um modo de vida, pautado em permanente conflito com o poder local, o que, possivelmente, é fator de expansão de capital social e fortalecimento de redes socioprodutivas. Trata-se de redes com inúmeros "nós" ligados por vínculos de amizade e parentesco, primeiramente, e comerciais e de trabalho, em segunda instância. Assim, a descrição de Bourdieu (1983) sobre o habitus expressa essa prática estruturante e estruturada de produzir e prestar serviço. Conforme o autor, habitus consiste em

[...] um sistema de disposições duráveis e transponíveis que, integrando todas as experiências passadas, funciona a cada momento como uma matriz de percepções, de apreciações e de ações - e torna possível a realização de tarefas infinitamente diferenciadas, graças às transferências analógicas de esquemas [...] (p. 65). 
Essas relações de solidariedade entre pares, ao mesmo tempo que sustentam as redes com suporte na confiança, formam um sistema de disposições dos trabalhadores informais no estabelecimento de suas redes. Nessa perspectiva, o capital social se mostra capaz de mobilizar os recursos para alcançar um grau elevado de bem-estar social (Coleman, 1990).

As vivências dos trabalhadores que se ocupam da produção e do comércio de roupas traça um tipo de rede social que pode ser denominada "rede socioprodutiva", pois a rede mantém e dá sentido às atividades realizadas, tanto no comércio direto da feira quanto nas pequenas fábricas informais, onde as costureiras são "colocadas para dentro" da casa do dono do negócio ou trabalham em suas casas em total informalidade. A unidade da ideia de "rede socioprodutiva" pode melhor contextualizar o objeto focalizado, pois as características dessa rede social informal não são ditadas pela tecnologia, apesar de serem afetadas por ela, e nem limitadas ou determinadas pelas estratégias organizativas, mas primeiramente fixadas pelas relações de confiança estabelecidas entre os participantes.

A noção de rede socioprodutiva reúne, portanto, as concepções de informalidade, rede social, e capital social de forma única. Trata-se de uma rede social porque os trabalhadores informais se relacionam em uma rede de solidariedade e confiança, permitindo, ou não, a inclusão de outros trabalhadores informais (familiares, vizinhos, parentes etc.), dependendo do conhecimento mútuo e da confiança, elementos essenciais do capital social. Por outro lado, além de alimentar os laços sociais e de confiança, subsidia a necessidade de produzir para viver e reforça o trabalho informal em uma rede de produção e/ou prestação de serviço: uma rede socioprodutiva. Da rede socioprodutiva participam o produtor, que pode exercer vários papéis, incluindo o de vendedor, atravessador, entre outros, e outros trabalhadores, em geral informais, que o auxiliam em troca de pequenas remunerações ou em troca de alimentação e abrigo, no caso de ligações familiares. Em todas essas ligações a confiança é fundamental. Tem-se, portanto, produtores mobilizando outros trabalhadores informais, temporários ou não, que os auxiliam a suprir as necessidades de produção e/ou vendas.

Por outro lado, a rede socioprodutiva possui um movimento na direção dos clientes, com os quais pode formar laços mais ou menos permanentes, o que pode propiciar o crescimento e a ampliação da rede com a contratação de novos trabalhadores.

A configuração dessas redes pode esclarecer as relações interpessoais daqueles que vivem e sobrevivem não apenas do comércio explícito das feiras, mas também do caminho entre a compra dos materiais e a produção do que é vendido nos boxes e nas ruas.

Os embates com o Poder Público, por outro lado, demonstram a força da rede social formada para dar conta de uma população urbana sem acesso a empregos formais, por sua inexistência, por escolha própria, ou, ainda, pela falta de qualidade do que é ofertado no setor formal. Os embates mostram, também, o capital social presente nas redes e indicam que os caminhos da formalidade, tal como proposto pelas autoridades locais, não satisfaz as necessidades reais dos produtores/ feirantes, cuja confiança reside no grupo.

Acredita-se que um estudo mais aprofundado, utilizando o aporte teórico-metodológico aqui proposto, possa subsidiar um melhor entendimento das redes socioprodutivas da informalidade e ajudar no estabelecimento de políticas públicas consistentes com as necessidades desse grupamento social.

\section{Referências}

Abramovay, R. (2002). O capital social dos territórios: Repensando o desenvolvimento rural. In E. Sabourin \& O. Teixeira (Orgs), Planejamento do desenvolvimento dos territórios rurais: Conceitos, controvérsias e experiências (pp. 113-128). Brasília, UFPB/CIRAD/EMBRAPA. 
Ayuku, D., Odero, W., Kaplan, C., Bruyn, R. de \& De Vries, M. (2003). Social network analysis for health and social interventions among Kenyan scavenging street children. Network, 18(1), 109-118.

Bourdieu, P. (1980). Le capital social. Actes de la Recherche en Sciences Sociales, 31 (1), 2-3.

Bourdieu, P. (1983). Questões de sociologia. Rio de Janeiro: Marco Zero.

Butts, C. T. (2009). Revisiting the foundations of network analysis. Science, 325(7), 414-416. doi: 10.1126/ science. 1171022 .

Cacciamali, M. C. (2000). Setor informal urbano e formas de participação na produção. São Paulo: Ed. IPE.

Carrieri, A. de P., Souza, M. M. P. de \& Almeida, G. O. (2008). Feirante ou barraqueiro? Identidades e estratégias na Feira do Jubileu. Revista Economia Ë Gestão, 18(17), 70-87.

Certeau, M. de (1994). A invenção do cotidiano. Petrópolis, RJ: Vozes.

Charmes, J. (2009). Concepts, measurements and trends. In J. P. Jütting \& J. R. de Laiglesia (Eds.), Is informal normal? Towards more and better jobs in developing countries (pp. 27-62). Paris: OECD Development Centres.

Coleman, J. S. (1988). Social capital in the creation of human capital. The American Journal of Sociology, 94(Suppl.), 95-120.

Coleman, J. S. (1990). The foundations of social theory. Cambridge, MA: Harvard University Press.

Dalbosco, E., Kuyumjian, M. M. M. (1999). Os desafios de compreender o trabalho informal. Revista Ser Social, 5(2), $23-44$.

Dantas, G. P. G. (2008). Feiras no nordeste. Mercator - Revista de Geografia da UFC, 7(13): 87-101.

Durães, B. J. R. (2002). "Trabalho informal”: Um paralelo entre os trabalhadores de rua da cidade de Salvador no século XIX e no século XXI. Caderno CRH, Salvador, 37(2), 289-308.

Eagle, N., Macy, M. \& Claxton, R. (2010). Network diversity and economic development. Science, 328(5981), 1029. 1031. doi: 10.1126/science. 1186605 .

France, M. de (2006). Por uma geografia das redes. In M. Santos (Ed.), A natureza do espaço: técnica e tempo, razão e emoção (4⿳亠丷⿵冂丶 ed., pp.176-190). São Paulo: Editora da USP.

Fredericks, K. A. \& Durland, M. M. (2005). The historical evolution and basic concepts of social network analysis. New Directions for Evaluation, 107,15-23. doi: 10.1002/ev.

Gagnon, J. (2009). Moving out of bad jobs: More mobility, more opportunity. In J. P. Jütting \& J. R. de Laiglesia (Eds.), Is informal normal? Towards more and better jobs in developing countries (pp. 115-142). Paris: OECD Development Centres.

Hatala, J.-P. (2006). Social network analysis in human resource development: a new methodology. Human Resource Development Review, 5(1), 45-71. doi: 10.1177/1534484305284318.

Instituto de Desenvolvimento do Trabalho. (2008). Pesquisa de emprego e desemprego na região metropolitana de Fortaleza. Relatório Anual de 2008. Fortaleza: IDT.

Jütting, J. P. \& De Laiglesia, J. R. (2009). Employment, poverty reduction and development: what's new? In J. P. Jütting \& J. R. de Laiglesia (Eds.), Is informal normal? Towards more and better jobs in developing countries (pp. 17-26). Paris: OECD Development Centres.

Lazari, M. (2010, 24 de agosto). Feirantes ignoram PM e iniciam comércio em prédio. Jornal O Povo [online]. Recuperado de http:/www.opovo.com.br/app/opovo/fortaleza/ 2010/04/26/noticiasjornalfortaleza,977225/feirantes-ignorampm-e-iniciam-comercio-em-predio.shtml

Lira, S. M. de (2008). Os aglomerados de micro e pequenas indústrias de confecções do agreste/PE: um espaço construído na luta pela sobrevivência. Revista de Geografia da UFPE, 23(1), 98-114. doi: 10.1590/S141552732008000400001.

Lyra, M. R. S. de B. (2005). Sulanca X Muamba: Rede social que alimenta a migração de retorno. São Paulo em Perspectiva, 19(4): 144-154. doi: 10.1590/S0102-88392005000400010.

Meneleu-Neto, J. (1994). Mercado informal: Roteiro para uma nova agenda de pesquisa. In Anais do II Encontro Nacional de Estudos do Trabalho ABET. Finep/FUSB/IGI.

Mesquita, E. C. (2008). Informalidade no mercado de trabalho de Fortaleza: Dimensão e características. Fortaleza, IDT. Recuperado de http://www.sineidt.org.br/PortalIDT/arquivos/ publicacao/INFORMALIDADE\%20DO\%20 MERCADO\%20DE\%20TRABALHO\%20DE\%20FORTALEZA.pdf 
Portes, A. (2000). Capital social: Origens e aplicações na sociologia contemporânea. Sociologia, Problemas e Práticas, 33(4), 133-158.

Putnam, R. D. (1996). Comunidade e democracia: A experiência da Itália Moderna. Rio de Janeiro: Editora da Fundação Getúlio Vargas.

Quinlan, M. (2009). We've been down this road before: Evidence on the health consequences of precarious employment in industrial societies, 1840-1920. In Anais da AAHANZBS Conference 2009 (pp. 1-11). Recuperado de http:// ses.library.usyd. edu.au//bitstream/2123/5733/1/Quinlan.pdf

Salvi, H. (2008, 30 de novembro). Aceita-se cartão de crédito. Jornal O Povo [online]. Recuperado de http://www.opovo. com.br/app/opovo/economia/2008/11/30/noticiasjornal economia,840713/aceita-se-cartao-de-credito.shtml

Sato, L. (2006). Visitando a feira livre: Notas sobre sua organização e seu trabalho. Tese de Doutorado, Instituto de Psicologia, Universidade de São Paulo, São Paulo.

Sato, L. (2007), Processos cotidianos de organização do trabalho na feira livre. Psicologia E⿱ Sociedade, 19 (Ed Esp 1), 95-102.

Silva, E. S. da, Santos, M. C., Silva, J. B. da (2010). Comércio Informal no centro de Fortaleza: Beco da Poeira e Feira da Sé. In Anais do XVI Encontro Nacional dos Geógrafos (pp. 1-10). Porto Alegre: AGB.

Suzigan, W., Furtado, J., Garcia, R., \& Sampaio, S. E. K. (2003). Sistemas Locais de Produção: mapeamento, tipologia e sugestões de políticas. In Anais do XXXI Encontro Nacional de Economia, 9 a 12 de dezembro de 2003 (pp. 1-21). Porto Seguro, BA.

Toniatti, M. (2008, 29 de abril). Espaço público: Território de ninguém. Jornal O Povo [online]. Recuperado de http:// www.opovo.com.br/app/opovo/fortaleza/2008/04/28/ noticiasjornalfortaleza,784547/espaco-publico-territoriobr-de-ninguem.shtml

\section{Endereço para correspondência}

reginaheloisamaciel@gmail.com, bosco_feitosa@yahoo.com.br, tgrm24@gmail.com, lumariamaia@gmail.com, marsellef@hotmail.com 